Supporting Information for:

\title{
Novel Insights into the Distribution of Reduced Sulfur Species in Prairie Pothole Wetland Pore Waters Provided by Bismuth Film Electrodes (BiFEs)
}

\author{
Brandon C. McAdams, ${ }^{\dagger}$ Rachel M. Adams, ${ }^{\dagger}$ William A. \\ Arnold, fand Yu-Ping Chin ${ }^{+*}$
}

*E-mail: chin.15@osu.edu, ph: (614) 292-6953

\section{Chemicals and Reagents}

3 Deionized water (DI; 18.2 $\mathrm{M} \Omega-\mathrm{cm}$ ) was produced with an Elix reverse osmosis and

4 Milli-Q deionization (Millipore: Molsheim, France). The aqueous atomic absorption

5 bismuth $(\mathrm{Bi})$ reference standard solution SB163-100 (1000 ppm $\pm 1 \%$, Fisher: Fair Lawn,

$6 \mathrm{NJ}), \mathrm{HCl}\left(34-37 \%\right.$ trace metal grade, Fisher: Fair Lawn, NJ), $\mathrm{HNO}_{3}(67-70 \%$ trace metal

7 grade, Fisher: Fair Lawn, NJ), and $\mathrm{NaOH}$ (10.05-9.05 N, Fisher: Fair Lawn, NJ), were used as

8 received and diluted with DI to make the solutions described hereafter. Solid $\mathrm{HgCl}_{2}$

9 (99.5+\%, Aldrich: Milwaukee, WI), $\mathrm{MnCl}_{2} \cdot 4 \mathrm{H}_{2} \mathrm{O}$ (100.4\%, J.T. Baker: Phillipsburg, NJ),

$10 \mathrm{FeSO}_{4} \cdot 7 \mathrm{H}_{2} \mathrm{O}(99+\%$, Alfa Aesar: Ward Hill, MA), sodium dithionite (min 87\%, EMD

11 Chemicals: Darmstadt, Germany), $\mathrm{Na}_{2} \mathrm{~S} \cdot 9 \mathrm{H}_{2} \mathrm{O}$ (98.0-103.0\%, Alfa Aesar: Ward Hill, MA),

12 Acetic acid, potassium salt (99+\%, Acros Organics: Geel, Belgium), NaCl (99.9\%, Fisher

13 Chemical: Fair Lawn, NJ), N,N-dimethyl-p-phenylenediamine sulfate (98\%, Aldrich:

14 Milwaukee, WI), and ferric chloride hexahydrate (>98\%, Sigma: St. Louis, MO) were used 15 by dissolving into DI or other solutions as described below. 


\section{Working Electrode Fabrication}

17 The first two series of steps for fabricating each type of working electrode were the

18 same. In the third series of steps, the working electrodes were plated with either Bi or $\mathrm{Hg}$

19 from solutions of one or the other.

20 1) The outer covering and inner metal sheath were stripped from roughly 18 to 20

21 inches of BNC cable still covered in the innermost plastic sheath. Approximately one inch of

22 the innermost plastic was then stripped from both ends of the cable. A one to one and half

23 inch length of $100 \mu \mathrm{m}$ diameter gold wire $(99.99 \%$ trace metal basis, Aldrich: Milwaukee,

24 WI) was then woven into a quarter to half an inch of the copper wiring on one end of the

25 cable, this connection was then soldered with 60/40 rosin core solder (RADIOSHACK:

26 Columbus, OH). A piece of polyether ether ketone (PEEK) tubing (ID: $2 \mathrm{~mm}$, OD: $3 \mathrm{~mm}$ ) was

27 then cut to about an inch less than the length of the BNC cable plus the soldered gold wire.

28 The PEEK tubing was filled with a two-part epoxy (105 resin and 205 hardener, West

29 Systems: Bay City, MI) using a plastic syringe and 13 gage flat-tipped needle. The tubing

30 was filled from the bottom up by lowering the needle as far as possible into the tubing

31 while holding it upright and pumping the epoxy out of the syringe slow enough that no air

32 bubbles formed in the epoxy. The BNC cable and gold wire were then lowered into the

33 epoxy-filled tube until the gold wire was at or just above the bottom of the PEEK tubing,

34 roughly an inch of the BNC cable should be sticking out of the top of the tubing. At this

35 point the framework of the $\mathrm{Au} / \mathrm{Hg}$ and BiFE electrodes was assembled. Parafilm (Beemis:

36 Neenah, WI) was then wrapped around the bottom of the electrode to prevent the epoxy

37 from draining out of the upright electrode as it was left to harden overnight. The copper

38 wire at the top of the electrode can also be wrapped in Parafilm during this step to 
39 minimize any corrosion that might occur from the ambient air reacting with the exposed 40 copper over time.

41 2) Once the epoxy had hardened, the tip of the electrode was trimmed with a

42 razorblade and then sanded with coarse and fine grit sandpaper applied to a Dremel tool to 43 create a planar surface composed of epoxy and the $100 \mu \mathrm{m}$ tip of the gold wire. The planar 44 surface of the gold wire was further polished with four different grits of diamond pastes:

$4515,6,1$, and 1/4 micron (Buehler: Lake Bluff, IL). A small dab of each paste was applied to a 46 polishing pad, and then a drop or two of polishing oil was used to soften the paste, allowing

47 it to spread evenly over the pad and facilitate polishing. This step is critical toward the 48 fabrication of the working electrode.

49 3) Immediately after polishing, the electrodes were transferred to solutions of either $5050 \mathrm{mg} \mathrm{L}^{-1} \mathrm{Bi}$ or $0.16 \mathrm{M} \mathrm{HgCl}_{2}$ for plating of $\mathrm{Bi}$ or $\mathrm{Hg}$ onto the polished Au wire. The $\mathrm{Bi}$

51 solution was made by diluting the $1000 \mathrm{ppm}$ Bi analytical standard into DI and buffering

52 with acetate to $\mathrm{pH}$ 4.5. Electrodes were plated by holding the gold surface at specific

53 potentials (Bi: $-0.3 \mathrm{~V}$ for $600 \mathrm{~s}$; $\mathrm{Hg}:-1.0 \mathrm{~V}$ for $250 \mathrm{~s}$ ) using a DLK-70 potentiostat with the Pt 54 counter electrode and the $\mathrm{Ag} / \mathrm{AgCl}$ reference electrode in the plating solutions. Once the $\mathrm{Bi}$ 55 was plated onto the Au surface, the BiFE working electrode was complete, but the $\mathrm{Hg}$ 56 electrode required an additional step. After the Hg electrode was plated, it was rinsed with

57 DI to remove any $\mathrm{Hg}$ on the surface, placed in a $1 \mathrm{M} \mathrm{NaOH}$ solution, and held at $-3 \mathrm{~V}$ with

58 the Pt counter electrode held at $3 \mathrm{~V}$ for at least 90 seconds. At this potential, hydrogen

59 peroxide formed at the Hg surface, amalgamating Hg into the Au surface. The finished

60 electrodes were then stored in $15 \mathrm{~mL}$ Falcon tubes filled with DI to ensure the tip of the 61 electrode did not dry out and corrode. 


\section{Calibration Conditions}

63 Calibrations were performed in a glass crucible cell by consecutive standard additions

64 of the target analyte in a $0.02 \mathrm{M} \mathrm{NaCl}$ solution made with DI. A conditioning potential

65 of $-0.1 \mathrm{~V}$ was applied for 40 seconds before running the square wave scan from $-0.1 \mathrm{~V}$

66 to $-1.8 \mathrm{~V}$ at $100 \mathrm{mV} \mathrm{s}^{-1}$ at a $100 \mathrm{nA} \mathrm{V}^{-1}$ current range. Sulfide calibration scans were run

67 from $-0.4 \mathrm{~V}$ to $-1.6 \mathrm{~V}$ to -0.4 and from $-1.6 \mathrm{~V}$ to $-0.4 \mathrm{~V}$ to $-1.6 \mathrm{~V}\left(\mathrm{CV}_{\mathrm{Lo}}\right.$ and $\mathrm{CV}_{\mathrm{Hi}}$, respectively $)$.

68 The limit of free sulfide detection was greater for $\mathrm{CV}_{\mathrm{Hi}}$ scans, and so those scans were the

69 most commonly used when measuring free sulfide in situ.

70 Prior to use, the glass cell was cleaned by soaking overnight with a $10 \% \mathrm{HNO}_{3}$ solution

71 and rinsed with DI. Before addition of the reduced analyte of interest, the $0.02 \mathrm{M} \mathrm{NaCl}$

72 solution was deoxygenated by purging with argon gas (Praxair: Danbury, CT) for at least

73 one minute per every $\mathrm{mL}$ of solution (e.g. 10 minutes for a $10 \mathrm{~mL}$ solution). Stock solutions

74 of $\mathrm{Mn}(\mathrm{II})$ and $\mathrm{Fe}(\mathrm{II})$ were prepared from solid-state standards of $\mathrm{MnCl}_{2} \cdot 4 \mathrm{H}_{2} \mathrm{O}$ and

$75 \mathrm{FeSO}_{4} \cdot 7 \mathrm{H}_{2} \mathrm{O}$ in $\mathrm{DI}$ acidified to $\mathrm{pH} 2$ with $\mathrm{HNO}_{3}$. Sodium dithionite was also added to the

$76 \mathrm{Fe}(\mathrm{II})$ stock solution to ensure all Fe was present as Fe(II). A thiosulfate signal could be

77 observed during Fe(II) calibration scans from this diothionite addition, but it occurred at a

78 potential that did not affect the Fe(II) calibration. ${ }^{2}$ Stock solutions of sulfide were made

79 with $\mathrm{Na}_{2} \mathrm{~S} \cdot 9 \mathrm{H}_{2} \mathrm{O}$ crystals in de-oxygenated $0.02 \mathrm{M} \mathrm{NaCl}$ inside an anaerobic glovebox (Plas

80 Labs: Lansing, MI) with a controlled atmosphere of $95 \% \mathrm{~N}_{2}, 5 \% \mathrm{H}_{2}$ (Praxair: Danbury, CT)

81 and an oxygen scrubbing Pd catalyst (Coy Laboratory Products Inc.: Grass Lake, MI). The

82 sulfide crystals were rinsed with DI and blotted with a low-lint wipe to remove surface

83 oxidation products prior to dissolving in water. Sulfide calibrations were performed inside

84 the same anaerobic glovebox within 24 hours of making the stock solution. Because the 
85 sulfide standard is inherently a strong base, $\mathrm{pH}$ was adjusted with deoxygenated $10 \% \mathrm{HCl}$

86 after every standard spike to between 7.9 and 8.1 to prevent oxidation of BiFE at more

87 basic $\mathrm{pH}$ values. Care was taken, however, to maintain the $\mathrm{pH}$ around 8 so as to prevent any

88 loss of sulfide as degassing $\mathrm{H}_{2} \mathrm{~S}$.

89 A separate calibration curve was conducted in PPR sediment pore waters in parallel

90 with a calibration measured in $0.02 \mathrm{M} \mathrm{NaCl}$ using the identical electrode to determine any

91 possible matrix effects. Unfiltered pore water supernatant was obtained by centrifuging P8

92 wetland sediments. These calibrations were found to be statistically similar (Figure S1).

93 From this test, we determined that the pore water matrix has a negligible effect, if any, on

94 the efficacy of the BiFE to quantify sulfide with the possible exception of the AVS

95 measurement as discussed in the paper.

\section{Pore Water Extraction by Squeezing}

97 Pore waters were extracted from the same cores, P7, P8-OW, and P8-VM, on which

98 voltammetric analyses were performed. Extraction was performed using Jahnke type

99 squeezers into nitrogen purged glass syringes through 30-75 $\mu \mathrm{M}$ filtration rods (Porex:

100 Fairburn, GA) and sealed with a metal Luer-lok cap onto the end of the syringe ${ }^{3-5}$. Squeezed

101 pore waters from P7 and P8 cores were analyzed for sulfide by methylene blue, to compare

102 with BiFE measured $\Sigma \mathrm{H}_{2} \mathrm{~S}$, and for dissolved organic carbon. Pore waters from T9 were also

103 extracted and analyzed for dissolved organic carbon, but not for sulfide by methylene blue

104 as voltammetry showed sulfide would likely be well below the detection limit of the

105 colorimetric assay (Figure S3). 


\section{Methylene Blue Analysis}

107 Methylene blue analyses were performed after Cline (1969) ${ }^{5}$. This method was

108 developed for use in natural waters and is free of temperature and salt effects. ${ }^{5}$ It can,

109 however, underestimate $\Sigma \mathrm{H}_{2} \mathrm{~S}$ in the presence of polysulfides. ${ }^{2,7}$ Bias due to polysulfides

110 should be negligible if polysulfides are present at low concentrations relative to total

111 hydrogen sulfide, ${ }^{7}$ and this has been demonstrated for previous work at this site. ${ }^{4}$ Duplicate

112 pore water samples were analyzed with freshly prepared sulfide standards. Sodium sulfide

113 stock solutions were prepared in an anaerobic glovebox with $\mathrm{Na}_{2} \mathrm{~S} \cdot 9 \mathrm{H}_{2} \mathrm{O}$ crystals and

114 deoxygenated DI as described for voltammetry calibrations.

115 The diamine reagent was prepared by dissolving $0.8 \mathrm{~g} \mathrm{~N}, \mathrm{~N}$-dimethyl-p-

116 phenylenediamine sulfate salt and $1.2 \mathrm{~g}$ ferric chloride hexahydrate in $20 \mathrm{~mL}$ of

117 deoxygenated $50 \%(\mathrm{v} / \mathrm{v}) \mathrm{HCl}$. Within minutes of sample collection, a $0.5 \mathrm{~mL}$ aliquot of each

118 sample was diluted 1:2(v/v) with deoxygenated DI and mixed with $80 \mu \mathrm{L}$ of diamine

119 reagent inside the previously described controlled-atmosphere glovebox. After 20 minutes

120 the mixture was diluted 1:50 (v/v) with DI and the absorbance measured at $670 \mathrm{~nm}$ using a

121 Shimadzu UV-1601 PC spectrophotometer with a 1-cm path length quartz cuvettes.

\section{DOC Analysis}

123 Dissolved organic carbon concentrations of squeezed pore waters were determined by

124 Pt-catalyst combustion and NDIR absorbance of the evolved $\mathrm{CO}_{2}$ using a Shimadzu TOC-V.

125 Before analysis, $1 \mathrm{~mL}$ of sample was filtered through pre-combusted $0.7 \mu \mathrm{m}$ (nominal)

126 glass fiber filters (Whatman: Buckinghamshire, UK) into $4 \mathrm{~mL}$ of DI acidified to $\mathrm{pH} \leq 2 \mathrm{with}$

127 trace metal $\mathrm{HCl}$ in order to dilute the DOC concentrations and acidify the sample. Samples 
128 were held for $\sim 48$ hours on ice in nitrogen-purged sealed glass syringes before the

129 filtration, dilution, and acidification step. Dilution into acidified DI was needed due to the

130 high native concentration of DOC and for the eventual removal of inorganic carbon.

131 Samples were held for no more than 24 hours at $4^{\circ} \mathrm{C}$ after this dilution step before analysis.

\section{Supporting Figures}

133 Figure S1 plots comparative calibrations of $\Sigma \mathrm{H}_{2} \mathrm{~S}$ performed in $\mathrm{DI}+0.02 \mathrm{M} \mathrm{NaCl}$ and in 134 unfiltered pore waters from P8.

135 Figure S2 visually portrays and diagrams the pseudo-in situ technique used.

136 Figure S3 plots Cathodic Square Wave scans of the T9 (recharge wetland) core.

137 Figure S4 plots sulfide and DOC with depth for P7, P8-OW, and P8-VM cores showing 138 deviation of sulfide from the DOC profile.

139 Figure S5 plots a calibration scan and an in-situ field scan of sulfide made with the BiFE 


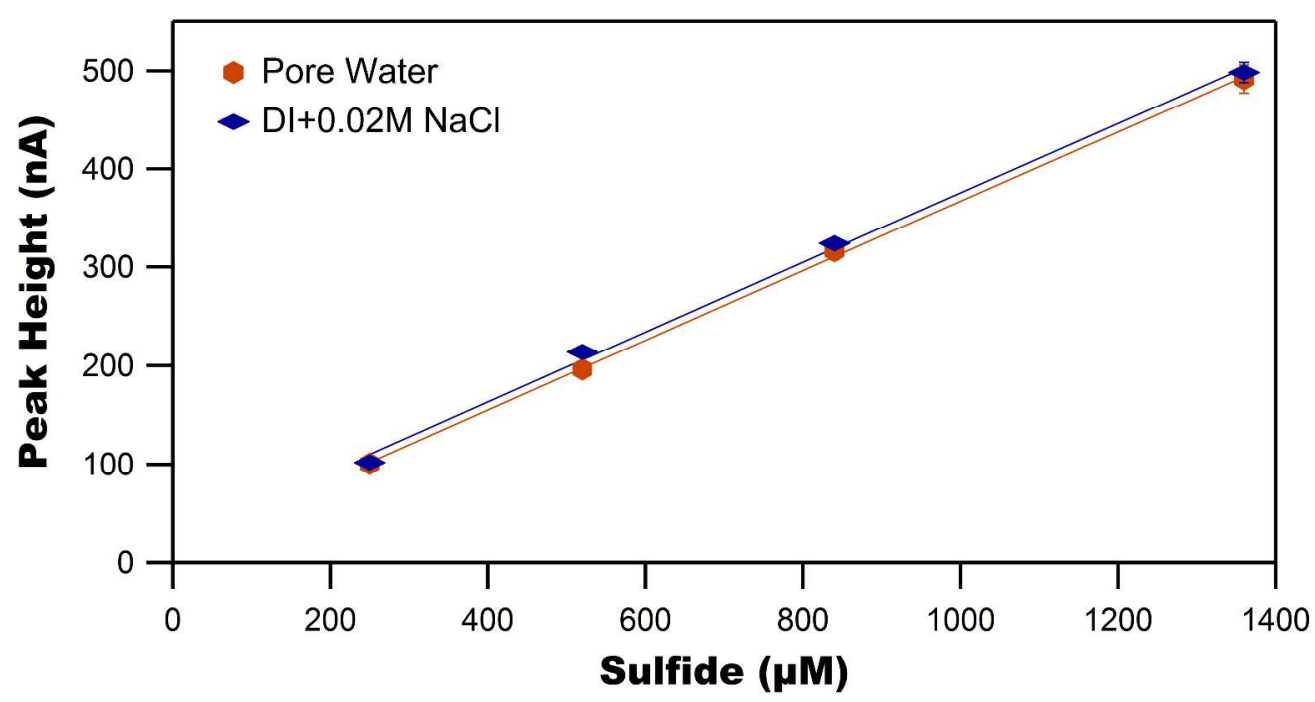

141 Figure S1: Comparative calibrations of $\Sigma \mathrm{H} 2 \mathrm{~S}$ performed in DI $+0.02 \mathrm{M} \mathrm{NaCl}$ and in unfiltered 142 pore waters from P8. Parameters of linear fits are as follows for DI+0.02M NaCl: $\mathrm{r}^{2}=0.998$, 143 Peak Height $=0.356 \pm 0.0114 *[$ Sulfide $]+21.9 \pm 9.72$; and for Pore Water: $\mathrm{r}^{2}=0.999$, Peak 144 Height $=0.353 \pm 0.00559 *[$ Sulfide $]+13.8 \pm 4.75$. 

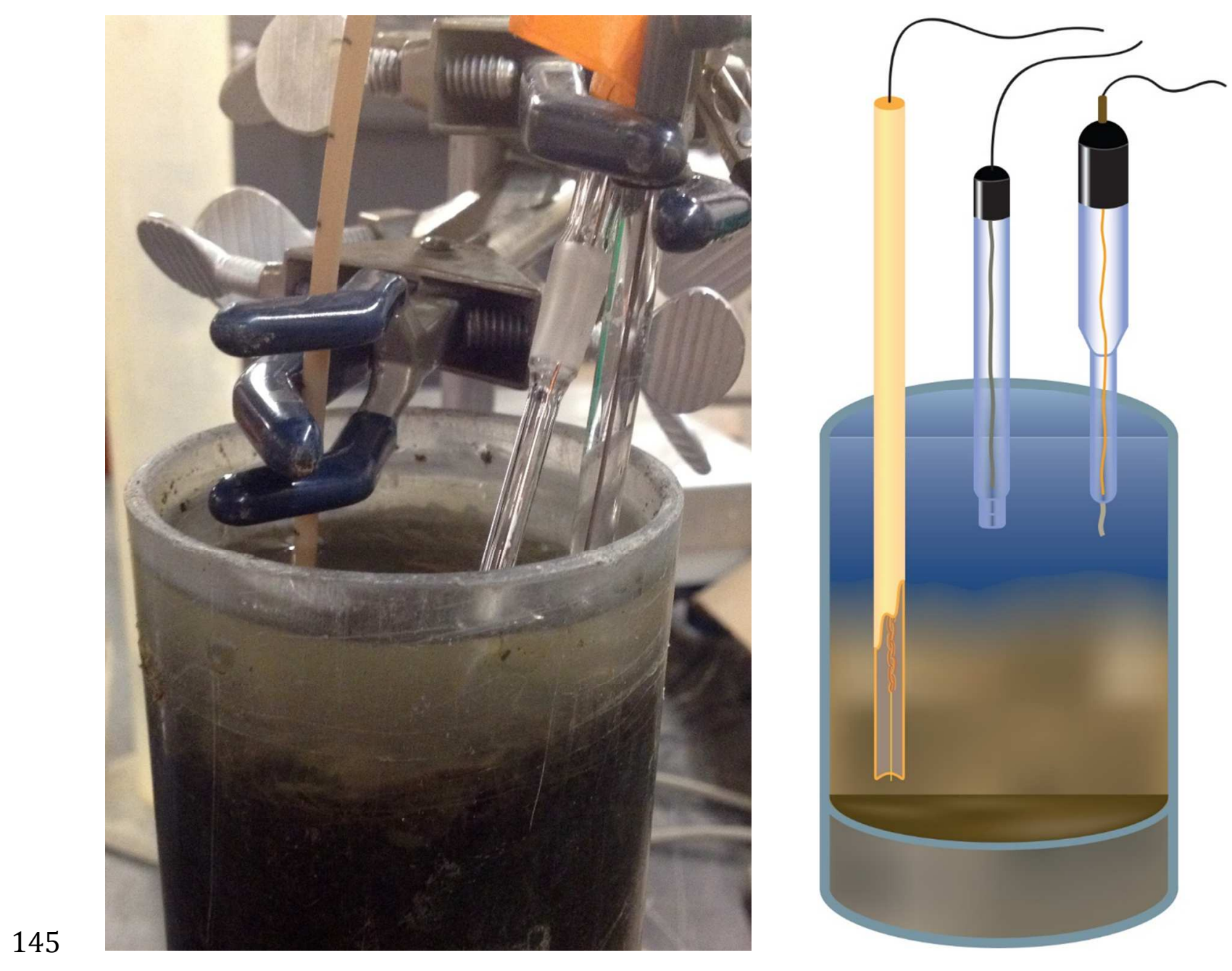

146 Figure S2: Picture (left) and diagram (right) of pseudo-in-situ technique showing the 147 reference and counter electrode suspended in the overlying water while the $\mathrm{Hg} / \mathrm{Au}$ or BiFE 148 working electrode is pushed into the core. Electrodes in the diagram are, from left to right, 149 working electrode, reference electrode, and counter electrode. 


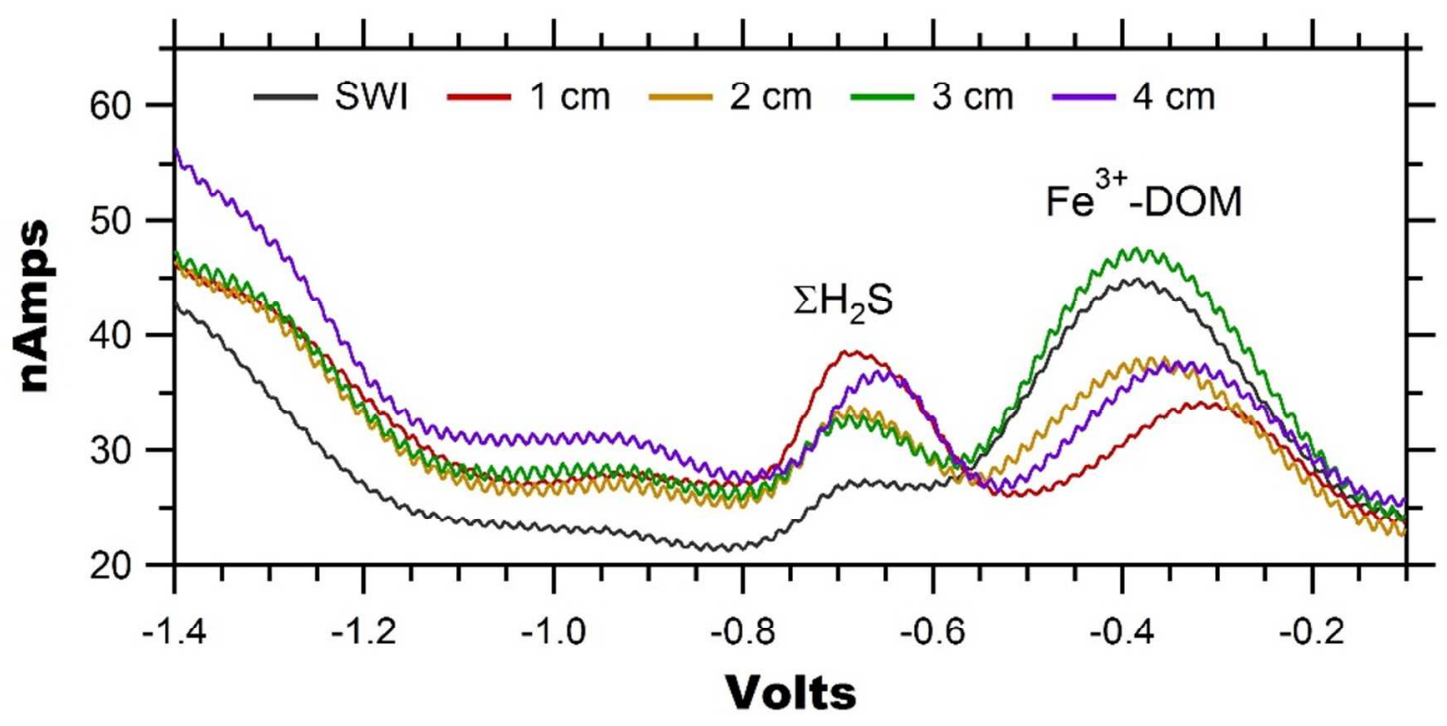

150

151 Figure S3: Cathodic square wave scans of the T9 core with depth showing a small sulfur 152 signal and the presence of $\mathrm{Fe}^{3+}-\mathrm{DOM}$ complexes, but no contribution from other redox 153 active species. 

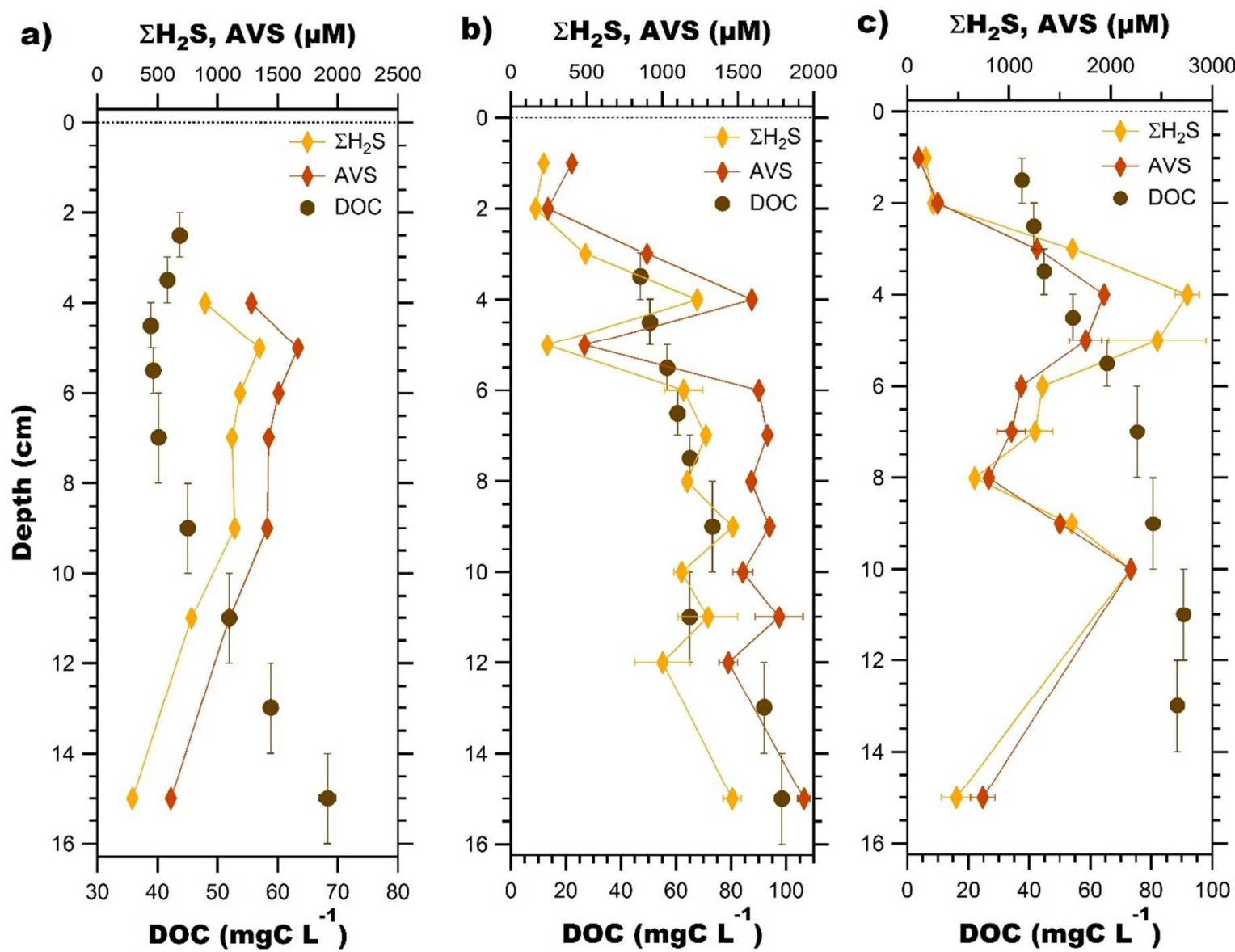

155 Figure S4: Depth profiles of dissolved organic carbon (DOC) and sulfide from a) P7, b) P8156 OW, and c) P8-VM cores labeled according to legends. In particular, a) and c) show 157 deviation of sulfide from the DOC profile. Vertical error bars on DOC points indicate the 158 vertical space squeezed from the core and integrated into that measurement. Horizontal 159 error bars are 1 standard deviation from the mean of at least two replicate measurements. 


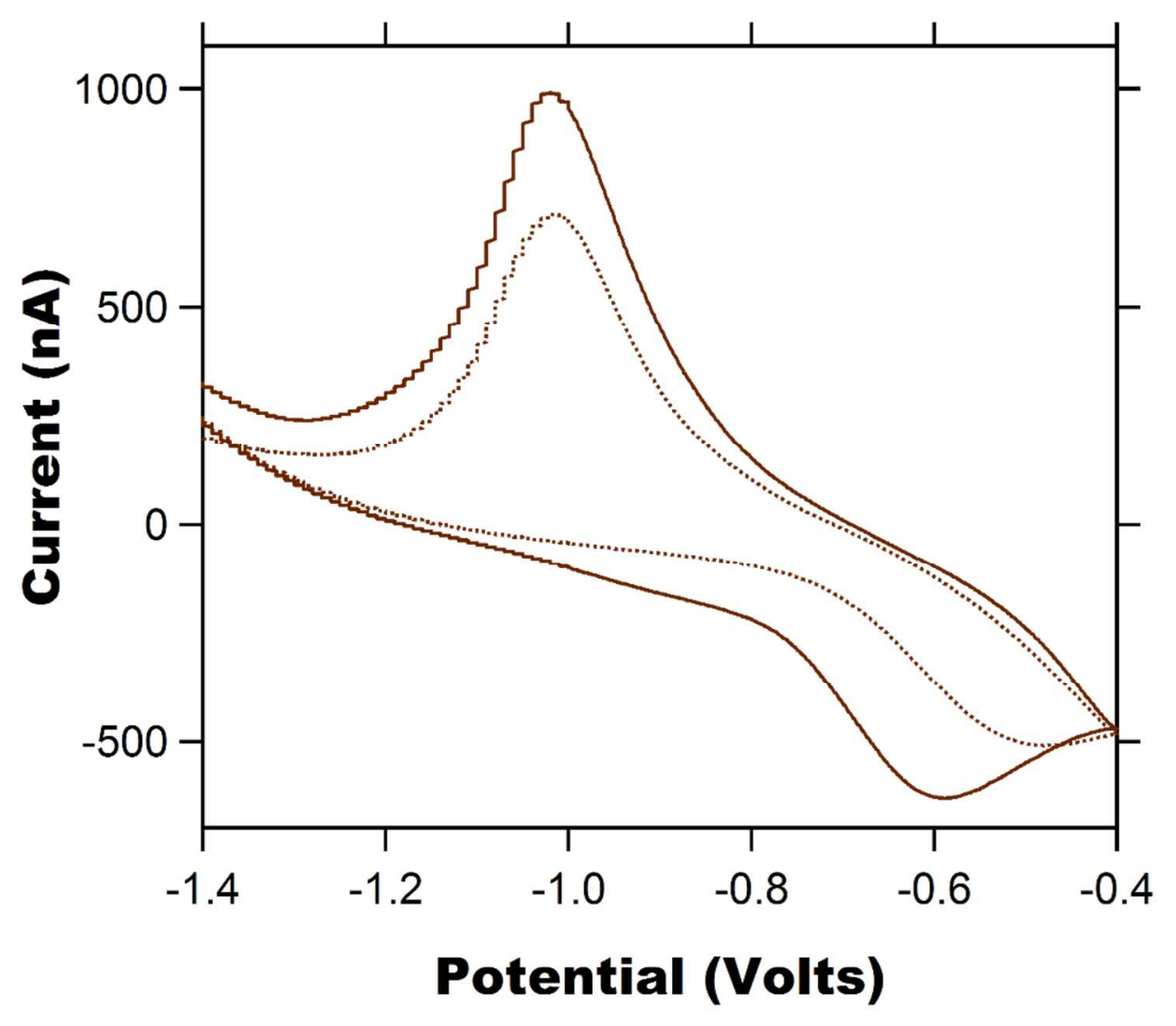

161 Figure S5: Calibration scan (solid line) and in-situ field scan (dotted line) of sulfide with 162 the BiFE plotted together for comparison. Note the in-situ anodic peak is broadened and the 163 peak minima shifted positively (-0.5V) compared to the calibration anodic peak which is 164 sharper with a more negative minima $(-0.6 \mathrm{~V})$ that allows the peak to be resolved before $1650.4 \mathrm{~V}$. Furthermore, the calibration scan is of a $\Sigma \mathrm{H}_{2} \mathrm{~S}$ concentration that is roughly $1 \mathrm{mM}$ 166 higher than the $\Sigma \mathrm{H}_{2} \mathrm{~S}$ concentration of the in-situ field scan. 


\section{References for Supporting Information}

(1) Waite, T. J.; Kraiya, C.; Trouwborst, R. E.; Ma, S.; Luther III, G. W. An Investigation in the Suitability of Bismuth as an Alternative to Gold-Amalgam as a working electrode for the In Situ Determination of Chemical Redox Species in the Natural Environment. Electroanal. 2006, 18, 1167-1172.

(2) Luther III, G. W.; Giblin, A. E.; Varsolona, R. Polarographic analysis of sulfur species in marine porewaters. Limnol. Oceanogr. 1985, 30, 727-736.

(3) Jahnke, R. A. A simple, reliable, and inexpensive porewater sampler. Limnol. Oceanogr. 1988, 33, 483-487.

(4) Zeng, T.; Ziegelgruber, K. L.; Chin, Y. P.; Arnold, W. A. Pesticide Processing Potential in Prairie Pothole Porewaters. Environ. Sci. Technol. 2011, 45, 6814- 6822.

(5) Ziegelgruber, K. L.; Zeng, T.; Arnold, W. A.; Chin, Y. P. Sources and composition of sediment pore-water dissolved organic matter in prairie pothole lakes. Limnol. Oceanogr. 2013, 58, 1136-1146.

(6) Cline, J. D. Spectrophotometric Determination of Hydrogen Sulfide in Natural Waters. Limnol. Oceanogr. 1969, 14, 454-458.

(7) Wang, F.; Tessier, A. Zero-Valent Sulfur and Metal Speciation in Sediment Porewaters of Freshwater Lakes. Environ. Sci. Technol. 2009, 43, 7252-7257. 